\title{
¿HOGARES SIN FAMILIA O FAMILIAS SIN HOGAR? UN ANÁLISIS SOCIOLOGICO DE. LAS FAMILIAS DE HECHO EN ESPANAA
}

\author{
Lluís Flaquer \\ Universitat Autònoma de Barcelona
}

Resum

En aquest treball l'autor dóna una ullada als darrers canvis sobrevinguts en l'àmbit de les formes familiars a Espanya, centrant-se especialment en l'aparició recent de les "families de fet" i de les "noves llars", en particular les unions consensuals i les families monoparentals. En el primer apartat de l'estudi presenta $i$ analitza els escassos materials empirics existents sobre la qüestio, procedents sobretot d'enquestes i de dades censals, mentre que en la darrera part tracta de descriure les transformacions experimentades per la familia occidental en el decurs de la passada dècada a través de la bipótesi d'una segona transició familiar, caracteritzada per la privatització de les normes familiars iper la intensificació del feminisme ide l'individualisme.

Resumen

En este trabajo el autor echa una ojeada a los áltimos cambios acaecidos en el ámbito de las formas familiares en España, centrándose especialmente en la aparición reciente de las "familias de hecho" y de los "nuevos hogares", en particular las uniones consensuales y las familias monoparentales. En el primer apartado del estudio presenta y analiza los escasos materiales empiricos existentes sobre la cuestión, procedentes principalmente de encuestas y datos censales, mientras que en la ultima parte trata de describir las transformaciones experimentadas por la familia occidental en el curso de la pasada década a través de la bipotesis de una segunda transición familiar, caracterizada por la privatización de las normas familiares y por la intensificación delfeminismo $y$ del individualismo.

Abstract

In this article the author surveys fresh developments of family forms in Spatn, especially focusing on the discussion of the recent rise of "factual families" and "new housebolds", i.e. non-marital cobabitation and oneparent families. In the first section be tries to present and analyse the scarce empirical material on the question available through national surveys and 
«Papers»: Revista de Sociologia

census data, while in the last part of the article an effort is made to describe the changes undergone by the Western family in the last decade through the bypothesis of a second family transition, characterised by the privatisation of family norms and the growtb of feminism and individualism.

\section{INTRODUCCIÓN"}

El significado de las palabras cambia a medida que se transforman ya sea los valores que les sirven de sustento ya sea los tipos sociales o las situaciones que describen. En otras ocasiones, cuando los vocablos están excesivamente marcados por connotaciones despectivas, hay que plantearse la necesidad de acuñar otros nuevos. En el ámbito de las relaciones familiares, donde estamos asistiendo en los últimos años a una profunda revolución en las actitudes y los comportamientos, hay términos como padrastro o madrastra, solterona, hijo ilegítimo, concubina o amancebamiento que ya no nos atrevemos a usar para aplicarlos a situaciones estructuralmente semejantes a las del pasado, pero cuyo sentido cabal se ha alterado sustancialmente.

Algo de eso sucede con los que viven solos. Compadecidos por sus congéneres o resignados ante su triste suerte en la sociedad de antaño, en la actualidad la imagen social que proyectan es de libertad y autosuficiencia, al menos en lo que respecta a los más jóvenes.

En el caso de las tradicionalmente llamadas «familias sin hogar» pasa algo parecido. Desde el siglo XVII, en que surge el modelo de familia nuclear en las clases burguesas y acomodadas de los países que habían emprendido con pie firme la Revolución Industrial, la historia de la familia se resume en una difusión lenta y constante de ese modelo entre las clases populares. La extensión de la educación a capas cada vez más amplias de la población, el influjo y el impacto creciente de los medios de comunicación de masas, el auge de las profesiones asistenciales, la provisión de subsidios sociales y pensiones por parte del Estado, por citar sólo algunos de los factores más relevantes que han ope-

"Una primexa versión de este trabajo se presentó como ponencia dentro del curso "Las transformaciones de la familia al final del siglo xx: La familia de hechon, impartido cn el marco de ta Universidad Internacional Menéndez Pelayo. Este curso, dirigido por Encarna Roca, catedrática de Derecho Civil Catalán de la Universidad de Barcelona, se celebró en Pedralbes (Barcelona) en julio de 1989. El autor agradece las críticas formuladas, tanto por los alumnos del curso como por otros docentes, que han contribuido a las mejoras sustanciales que incorpora esta revisión. 
rado en los países más desarrollados, fueron imponiendo el sistema de familia nuclear como ideal a seguir mayoritariamente por la población. De esta forma, las restantes formas familiares de raíz no burguesa han pasado a ocupar una posición marginal o bien se hallan en trance de desaparición total. Esto ha supuesto un frente de avance triple. Por una parte, con el impacto de la industrialización y la penetración del capitalismo en el campo, se produjo una fuerte y progresiva erosión de los sistemas familiares tradicionales propios de ciertas regiones agrarias, donde la familia nuclear se ha ido implantando pattlatinamente. En segundo lugar, con la difusión de los valores individualistas, también ese modelo se ha ido introduciendo en los barrios obreros de las grandes ciudades industriales donde predominaban unas formas no estrictamente nucleares basadas en la solidaridad entre parientes y en el colectivismo de clase. Por fin, el tercer frente de penetración se ha compendiado en la lucha contra las «familias sin hogar», familias de clase baja que no se amoldaban a la pauta dominante pero que carecían de la fuerte estructuración de las familias campesinas u obreras tradicionales. Me refiero a aquellas familias marcadas por la miseria, la pobreza, la ilegitimidad, el abandono del padre, la prostitución o la delincuencia; hogares rotos que constituían el centro de preocupación de las autoridades en materia de servicios sociales y cuyas características problemáticas justificaban su intervención.

Aunque es posible que en la actualidad el problema de los hogares rotos nos parezca acotado a determinados ambientes marginales, si miramos el problema desde una perspectiva histórica nos percataremos de que ha habido que recorrer un largo trecho para Ilegar a la situación presente. En los inicios de la Revolución Industrial, ilegitimidad, ausencia de reconocimiento de la paternidad y abandono de niños eran fenómenos que muchas veces corrían parejos y que a juzgar por los testimonios de que disponemos sobre esa época eran bastante frecuentes. La bastardía como estigma social, la inclusa o el hospicio como destino inexorable, los niños expósitos, abandonados o huérfanos, el distinto trato jurídico y social que recibían los hijos según fueran legítimos, naturales $o$ adulterinos son fenómenos bien documentados tanto por los historiadores sociales del presente como por los novelistas realistas de la época.

Según nos dicen los expertos, en la segunda mitad del siglo XIX empiezan a declinar la tasa de ilegitimidad y el número de niños abandonados por cada cien nacidos, hasta quedar reducidos a niveles insignificantes en las últimas décadas del presente siglo, al tiempo que se produce un ascenso del número de hijos legitimados por cada cien hijos ilegítimos. Sin duda, en esos cambios confluyen factores tales como una mayor sensibilidad hacia el valor de la infancia y la necesidad de su protección, un sentimiento favorable a la igualdad de los hijos en particular y de los ciudadanos en general $y$, por último, un aumento de los niveles de prosperidad material en todas las clases de la sociedad. 
De esta forma, se cosecharían los frutos de la lucha de la respetabilidad burguesa contra la ilegitimidad en la medida en que ésta representaba una desviación de los patrones establecidos de familia y de matrimonio.

A mi juicio, en la actualidad nos hallamos en un momento de ruptura, ante una coyuntura que cabe calificar de segunda transición familiar, expresión que aclararé más adelante. Si hasta hace poco la ilegitimidad se hallaba marcada por unas connotaciones de marginalidad económica y cultural, de rechazo hacia los valores de la infancia y de oprobio social, en la actualidad se está perfilando una tendencia a la difuminación de la barrera existente entre legitimidad e ilegitimidad. No se trata tan sólo de un movimiento que tiene su traducción en la desaparición de las viejas discriminaciones jurídicas entre hijos legítimos y naturales, sino en un profundo cambio de la sensibilidad social en lo que respecta a la consideración y respeto que merecen por parte de sus semejantes aquellas personas - ya sean homosexuales, parejas unidas consensualmente o madres solteras- que desafían abierta y públicamente las pautas sometidas antaño a un rígido control. A esas personas - muchas veces con trabas y dificultades, hay que decirlo- se les reconoce cada vez más su derecho a la intimidad y a la vida privada, derecho que va arrumbando antiguos prejuicios y estigmas sociales.

Este trabajo sobre las familias de hecho en España se estructura en dos partes. En su primera parte se hace un análisis estadístico descriptivo de los principales tipos de familias de hecho en España, en especial de las llamadas parejas cohabitantes y de las familias monoparentales. En la segunda parte se esboza una reflexión sobre los cambios que se están produciendo en el horizonte familiar en relación con la desinstitucionalización del matrimonio y la crisis de la familia nuclear, tratando de sondear sus efectos para la vida social a corto y a medio plazo.

\section{FAMILIAS DE HECHO Y NUEVAS FORMAS DE HOGAR}

Como en muchas otras ocasiones, la rapidez de la evolución social ha pillado desprevenidos a los sociólogos y los acontecimientos se han adelantado a sus previsiones. Al final, el dinamismo y el carácter proteico de la realidad se han acabado imponiendo y en la actualidad existe un interés creciente entre los especialistas por los fenómenos familiares que antaño hubicran caído bajo la rúbrica de la marginalidad. A diferencia de lo sucedido en otras naciones occidentales donde, al hallarse la estructura familiar mucho más avanzada que en nuestro país, hace ya más de una decena de años que se vienen investigando sociológicamente las familias de hecho, en España su estudio aún está en mantillas. A decir verdad, aquí los pioneros de esta especialidad fueron los juristas, 
quienes, acuciados por el apremio de los casos que se planteaban ante los tribunales sobre los derechos de los cohabitantes, la situación jurídica de sus hijos y los conflictos de intereses en los litigios de separación, empezaron a interesarse por el tema.

Desde un punto de vista sociológico la primera constatación es la escasez del material existente sobre el asunto', si bien eilo pueda ser excusable debido a que todavía nos estamos refiriendo a fenómenos realmente minoritarios, con un peso específico muy reducido en la población total. Según los datos del censo de 1981, el último disponible, el 60 por 100 de la población española vivía en hogares nucleares, o sea, aquéllos formados por una pareja casada con algunos de sus hijos menores y sin la presencia de otras personas. En su conjunto, el 84 por 100 de la población residía en hogares que, a causa de la presencia de hijos, denotaban algún tipo de familia. Las personas que vivían solas no alcanzaban el 3 por 100 de la población y las que lo hacían en hogares sin núcleo de dos o más personas apenas superaban el 2 por 100.

Sin embargo, si consideramos desde una perspectiva comparativa internacional y dinámica los datos de lo que se podría llamar los «hogares sin familia», o sea de aquéllos que no incluyen en su seno hijos inmaduros, advertimos que es muy probable que en los próximos años esos valores aumenten de manera substancial. Por ejemplo, entre 1970 y 1981, en España las personas que viven solas se incrementaron en un 64 por 100 y en países como Francia suponen ya la décima parte del total de sus habitantes. En ciudades como París, de cada dos unidades de convivencia, una está constituida por una persona que vive sola.

Asimismo, en Estados Unidos, entre 1970 y 1980, según datos aportados por Emilio Lamo de Espinosa (1983: 11), «lo más notable es el crecimiento de los hogares no familiares. De los 15,7 millones de nuevos hogares que se crearon en el período citado, el 55,6 por 100 no son familiares; además, del 44,4 por 100 restante, la mitad sólo tienen un cabeza de familia. De este modo sólo el 22 por 100 de los nuevos hogares son familias completas. Los no familiares han crecido un 73,5 por 100 , seis veces más deprisa que la población». Por su parte, Salustiano del Campo y Manuel Navarro, dos sociólogos especialistas en temas familiares, al comentar también la evolución que se ha producido en la familia americana entre 1970 y 1980 , afirman que «la tasa de nupcialidad (...)

1 A pesar de lo dicho, scría injusto olvidar las contribuciones recientes al conocimiento de las familias de hecho en España por dos obras notables: Anna AI.ABART, Anna Cabrê, Andreu DOMingo, Assumpta FABRE y Verena STOLCK: La cohabitación en Esparia: Un estudio en Madrid y Barcelona, Madrid: Centro de Investigaciones Sociológicas, 1988; Julio Iglesias bi: Ussel (ed.), Las familias monoparentales, Madrid: Instiouto de la Mujer (Ministerio de Asuntos Sociales), 1988. 
declinó en ese período el 17 por 100, mientras que el número de parejas no casadas que vivían juntas se triplicó, pasando de 523.000 en 1970 a 1.560 .000 en 1980 y estando presente cuando menos en la cuarta parte de ellas un hijo menor de 15 años, procedente casi siempre del matrimonio anterior de uno de los miembros" (Del Campo \& Navarro, 1985: 6).

Cito todas esas cifras para poder situar en perspectiva los datos que seguirán referidos a España, mucho menos espectaculares. En las ciencias sociales, lo que cuenta no es tan sólo el volumen de los hechos o comportamientos que se dan en la actualidad, sino también las tendencias de cambio que se perfilan, ya que son ellas las que conforman los ideales de las futuras generaciones $\mathrm{y}$, andando el tiempo, llegan a gestar un mundo radicalmente distinto al presente.

Por ejemplo, cuando cito a mis estudiantes de sociología las cifras disponibles sobre la cohabitación en España, quedan pasmados, sonríen y sugieren que probablemente están equivocadas. Este asombro es comprensible teniendo en cuenta que en el mundo universitario la cohabitación anterior al matrimonio es mucho más frecuente que en el resto de los sectores sociales. De hecho, esta sorpresa es reveladora de las diferencias de percepción del colectivo estudiantil con respecto al grueso de la población, pero al mismo tiempo es indicativa de cuál pueda ser la proyección futura de la situación actual, dada la influencia que tendrán en la opinión pública del mañana los estudiantes de hoy. Como hemos dicho antes, la familia nuclear se gestó entre las clases burguesas del siglo xviII, que a la sazón constituían una minoría, incluso en los países que habían iniciado el camino de la industrialización; pero ese embrión, con el trascurso del tiempo, llegó a conformar el modelo del futuro.

De entre la variedad de familias de hecho voy a destacar tan sólo dos que son aquéllas que más han centrado la atención de los sociólogos de la familia y sobre las cuales existe una documentación más abundante: las familias monoparentales y las tniones de hecho.

Las familias monoparentales son aquéllas que están formadas por un padre o una madre solos con sus hijos inmaduros. Desde una perspectiva censal los hogares monoparentales son aquéllos en que un hombre o una mujer solos conviven con sus hijos solteros. Esta definición, como veremos más adelante, plantea problemas, ya que en España buena parte de estos hogares están formados por padres o madres ancianos que viven con algtno de sus hijos adultos célibes.

Desde el punto de vista de su formación, las familias monoparentales pueden agruparse en tres grandes apartados. Tradicionalmente eran fruto de la ruptura del grupo famillar por la muerte de uno de los dos esposos y, en gran parte, se hallaban encabezadas por mujeres viudas. Un segundo caso, cada día más frecuente, es el de aqutellos hogares de este tipo que se forman por sepa- 
ración o divorcio, tras el cual la mujer sigue conviviendo con sus hijos y se convierte en cabeza de una familia monoparental. En tercer lugar, forman hogares monoparentales las madres solteras que viven solas con sus hijos. Julio Iglesias de Ussel (1986) destaca también en la génesis de las familias monoparentales el abandono de familia, la adopción por solteros, la hospitalización, la emigración, o la encarcelación de uno de los rniembros de la pareja $y$, por último, su trabajo en localidades distanciadas.

Al lector avisado no se le habrá escapado el hecho de que los tres grandes tipos de familias monoparentales que hemos distinguido se relacionan, en lo que respecta a su formación, con el estado civil ds su cabeza de familia. La Tabla 1 muestra la distribución de los hogares de un solo progenitor en Francia, en 1982, según el sexo, la edad y el estado civil de la persona principal, lo que permite deducir aproximadamente el perfil de las clases de familias monoparentales a que hemos hecho referencia. Lamentablemente, en España no disponemos de un cuadro de características parecidas puesto que los responsables del Instituto Nacional de Estadística, que presentan innumerables tablas

\section{TABLA 1}

Hogares monoparentales según el sexo, la edad y el estado civil de la persona principal. Francia, 1982

\begin{tabular}{lccccc}
\hline \multicolumn{7}{c}{ Edad del progenitor solo } \\
\hline Sexo y estado civil & $15-24$ años & $25-34$ años & $35-44$ años & $\begin{array}{l}\text { } \\
\text { o más }\end{array}$ & Total \\
\hline Los dos sexos & 4,0 & 24,3 & 29,2 & 42,5 & 100 \\
\hline Hombres & 1,1 & 13,3 & 28,2 & 57,4 & 100 \\
Solteros & 12,0 & 37,6 & 21,7 & 28,7 & 100 \\
Casados-separados & 1,0 & 18,8 & 32,3 & 47,9 & 100 \\
Viudos & 0,2 & 3,4 & 14,3 & 82,1 & 100 \\
Divorciados & 0,2 & 16,0 & 41,9 & 41,9 & 100 \\
\hline Mujeres & 4,5 & 26,2 & 29,4 & 39,9 & 100 \\
Solteras & 17,0 & 43,5 & 23,7 & 15,8 & 100 \\
Casadas-separadas & 4,7 & 31,2 & 32,6 & 31,5 & 100 \\
Viudas & 0,5 & 5,8 & 18,2 & 75,5 & 100 \\
Divorciadas & 2,2 & 32,7 & 39,3 & 25,8 & 100 \\
\hline
\end{tabular}

Fuente: Censo francés de 1982, citado por LE GALL et MARTIN (1987), p 23. 
sobre monoparentalidad en los resultados nacionales del censo, de forma inexplicable han omitido distribuir los contingentes del tipo de hogar que nos interesa según el dato esencial del estado civil del cabeza de familia.

En España (1981) existen unos 600.000 hogares monoparentales, que alcanzan la cifra de 700.000 si incluimos los que comprenden otras personas ajenas al núcleo. Ello representa casi un 6 por 100 del total de los hogares (un 7 por 100 en el segundo supuesto). Por otra parte, la proporción de los hogares monoparentales encabezados por mujeres representa en nuestro país el 83 por 100 del total. Si tenemos la tentación de comparar estos datos con los existentes a nivel occidental, volvemos a tropezar con nuevos problemas. Como hemos dicho antes, gran parte de los hogares que figuran como familias monoparentales en el censo español de 1981 no son tales, dado que los hijos que viven en ellos ya no son inmaduros. En efecto, según los datos aportados por el propio censo, la proporción de madres solas con hijos solteros el menor de los cuales tenga más de 16 años con respecto al total de madres solas con hijos solteros representa el 67.6 por 100 . Y el porcentaje de los núcleos formados por una madre sola con todos sus hijos solteros menores de 16 años sobre el total de los núcleos monoparentales encabezados por mujeres tan sólo alcanza el 16.8 por 100 . Ello significa que gran parte de los datos sobre monoparentalidad extraídos del censo tienen muy poca validez, puesto que se refieren a una realidad que muy poco tiene que ver con la problemática asociada con las familias de un solo progenitor.

La Tabla 2 confirma cuanto llevamos dicho al tiempo que nos da algunas pistas para interpretar este fenómeno. Si distribuimos los núcleos monoparentales según la edad del padre o de la madre y su zona de hábitat, constataremos que más de tres cuartas partes de los mismos (exactamente el 70.5 por 100) tienen un progenitor de 45 más años. Además, en las zonas menos urbanizadas es donde se hallan más núcleos a cargo de padres o madres de más de 65 años. Ello significa que es muy probable que la «monoparentalidad censal» corresponda sobre todo a formas que constituyen subproductos de la desestructuración familiar en regiones duramente castigadas por la emigración.

Desgraciadamente no es posible calcular la tasa de crecimiento de los hogares monoparentales entre 1970 y 1981 , puesto que el censo de 1970 tan sólo nos da el número de núcleos monoparentales, pero no de hogares del mismo tipo. Sin embargo, podemos computar el incremento de núcleos monoparentales entre esas dos fechas, que tan sólo ha sido del 3,3 por 100. Esta cifra no es concluyente, dadas las reservas que hemos hecho hace un momento. De todas formas, en 1970 el porcentaje de los núcleos encabezados por mujeres $(78,4$ por 100) era bastante más bajo que diez años después. Tampoco es muy ilustrativa la distribución territorial de los hogares monoparentales por provincias ni ofrecen resultados muy significativos los análisis de correlaciones 
hechos con diversas variables socioeconómicas. Habrá que esperar a disponer de los datos del próximo censo o bien será preciso hacer encuestas especializadas sobre el asunto con objeto de poder aclarar todos esos puntos dudosos.

Sobre la segunda forma de familia de hecho, aquétla que incluye las parejas unidas consensualmente, disponemos de muy poca información a través de los datos certsales. Según el Instituto Nacional de Estadística, a partir del censo de 1960 se clasificaron como casadas las personas unidas de hecho en forma estable. Si este criterio es seguido de forma coherente no sólo resultan confundidos en una misma categoría los hogares formados por personas casadas legalmente o unidas consensualmente, sino que incluso en las distribuciones de los hogares según el estado civil de la persona principal los cohabitantes

\section{TABLA 2}

Núcleos monoparentales según la edad del padre o la madre y la zona de residencia: España, 1981

\begin{tabular}{lrrrrrrr}
\hline Zona de residencia & Total & -25 & $25-34$ & $35-44$ & $45-54$ & $55-64$ & $65+$ \\
\hline Zona rural & 190603 & 3444 & 9620 & 15594 & 33548 & 40153 & 88244 \\
Zona intermedia & 131517 & 2786 & 8011 & 13399 & 27390 & 28871 & 51060 \\
Zona urbana 1 & 130536 & 3230 & 10484 & 15562 & 29199 & 30145 & 41916 \\
Zona urbana 2 & 53918 & 1682 & 5120 & 7294 & 12264 & 12152 & 15406 \\
Zona urbana 3 & 172943 & 4803 & 17215 & 23512 & 38983 & 37370 & 51060 \\
Zona urbana 4 & 179005 & 3621 & 15412 & 23440 & 39563 & 39514 & 57455 \\
\hline Total & 858522 & 19566 & 65862 & 98801 & 180947 & 188205 & 305141 \\
\hline
\end{tabular}

\begin{tabular}{lcrrrrrr}
\hline Zona de residencia & Total & -25 & $25-34$ & $35-44$ & $45-54$ & $55-64$ & $65+$ \\
\hline Zona rural & 100,0 & 1,8 & 5,0 & 8,2 & 17,6 & 21,1 & 46,3 \\
Zona intermedia & 100,0 & 2,1 & 6,1 & 10,2 & 20,8 & 22,0 & 38,8 \\
Zona urbana 1 & 100,0 & 2,5 & 8,0 & 11,9 & 22,4 & 23,1 & 32,1 \\
Zona urbana 2 & 100,0 & 3,1 & 9,5 & 13,5 & 22,7 & 22,5 & 28,6 \\
Zona urbana 3 & 100,0 & 2,8 & 10,0 & 13,6 & 22,5 & 21,6 & 29,5 \\
Zona urbana 4 & 100,0 & 2,0 & 8,6 & 13,1 & 22,1 & 22,1 & 32,1 \\
\hline Total & 100,0 & 2,3 & 7,7 & 11,5 & 21,1 & 21,9 & 35,5 \\
\hline
\end{tabular}

Fuente: Lluis FLAQUER y Joan SOLER, Permanencia y cambio en la familia española, Madrid: Centro de Investigaciones Sociológicas, 1990. 
"Papers»: Revista de Sociologia

aparecen como casados sin que sea posible distinguirlos entre sí. Es obvio que este procedimiento es insatisfactorio y que no favorece precisamente la claridad, por lo que es de desear que en el próximo censo se distinga la unión consensual como forma de convivencia, dato que se agregaría al estado civil de aquellas personas no casadas que así lo indicaran.

Según las estimaciones de Salustiano del Campo (1984: 16), referidas a 1980 , en España vivía en cohabitación tan sólo un 0,37 por 100 de la población de más de 18 años. Ello representa unas 90.000 personas, tres cuartas partes de las cuales son solteras. Por otra parte, en la Encuesta sobre las condiciones de vida y hábitos de la población del área metropolitana de Barcelona, realizada en 1986 por un equipo del Departamento de Sociología de la Universidad Autónoma de Barcelona, se halló que formaban uniones consensuales alrededor de un 1 por 100 de los entrevistados de una muestra representativa de la población de más de 18 años. Es difícil comparar los dos datos, ya que la primera encuesta se refiere al total de España y fue realizada en 1980, mientras que la segunda es de 1986 y su ámbito se reduce tan sólo a una zona urbana tan dinámica como la conurbación barcelonesa. Por otra parte, la encuesta de Barcelona distingue la cohabitación como si fucra un estado civil, sin que podamos saber qué proporción de separados, divorciados, viudos y solteros se hallan conviviendo maritalmente con sus compañeros.

Utilizando los datos de la encuesta de Salustiano del Campo podemos calcular el porcentaje de las parejas cohabitantes con respecto al total de parejas corresidentes, casadas y no casadas, que alcanza tan sólo el 0,51 por 100. Esta cifra contrasta con la que hallamos en algunos países europeos como Francia (6 por 100), República Federal de Alemania (7 por 100) o Suecia (15 por 100) (Roussel, 1986).

No cabe duda de que en la mayoría de los países de Occidente el incremento espectacular experimentado por las uniones de hecho se ha producido tan sólo en años recientes, sobre todo entre las parejas jóvenes. El interrogante que se plantea es si cabe interpretar la cohabitación como una etapa de transición que conduce a las primeras nupcias o si, al contrario, podemos hablar de la desinstitucionalización del matrimonio. En algunos países como Suecia esta práctica se ha generalizado hasta tal punto que según Jan Trost (1978), casi la totalidad de los suecos casados han cohabitado durante algún tiempo antes de llegar al matrimonio.

Sin duda, según los datos que acabamos de presentar, en España la cohabitación es aún un fenómeno minoritario, restringido a ciertos sectores educados de la clase media. Según la tipología elaborada por un equipo del Ccntro de Estudios Demográficos de la Universidad Autónoma de Barcelona (Alabart et al., 1988), tres son las formas más corrientes de cohabitación en las 
grandes metrópolis españolas. En primer lugar, se hallan aquellas personas que se unen consensualmente por problemas sociales, económicos o legales. Este grupo constituye una supervivencia de la cohabitación tradicional como fenómeno marginal propio de las clases más desfavorecidas de la sociedad. Según uno de los autores de este estudio (Domingo, 1989), «dentro de este grupo de cohabitantes forzados por problemas sociales o institucionales, se engloban aquellas personas que viven su situación con conciencia de ilegalidad forzada, es decir, aquellos casos en que ambos miembros de la pareja, o uno de ellos, sienten su situación como anómala, viendo el matrimonio como única forma de normalización a veces inalcanzable. En este grupo encontramos a aquellas personas pertenecientes a los estratos de la población más bajos que, insertos o rozando los límites de la marginalidad, no se casan por razones esencialmente materiales, considerando muchos de ellos su relación como algo efímero, como un "apaño"».

La segunda categoría está formada por los llamados "cohabitantes ideológicos»--herederos de los movimientos de liberación sexual de los años sesenta-, que consideran la unión libre como un acto de militancia. Éstos «se autodefinen claramente como grupo opuesto al matrimonio, presentándose como alternativa al mismo por diversas razones, entre las que destacan, de un lado, las de carácter antiinstitucional: el resistirse a la intromisión del Estado en sus vidas privadas y el profesar una desafección militante hacia la Iglesia Católica» (Domingo, 1989).

En tercer lugar, cabe citar el contingente más numeroso, integrado por aquellas personas, generalmente fóvenes y solteras, que conviven maritalmente sin negar la posibilidad de casarse en un futuro más o menos lejano. Estos cohabitantes "no definen su situación como perpetua, desembocando muchas veces en el matrimonio, otras en la ruptura y otras manteniéndose en la continuidad. La cohabitación así practicada puede ser vivida como un periodo transitorio, ensayando, parece ser, su relación de cara a un futuro común; lo que ha venido en llamarse "matrimonio a prueba" (Domingo, 1989).

\section{LA SEGUNDA TRANSICIÓN FAMILIAR}

Una de las razones esgrimidas con más frecuencia para justificar ya sea la legitimidad de la cohabitación o de la ruptura matrimonial es la consideración de que en la actualidad el matrimonio ha pasado a ser un mero contrato privado, cuya vigencia y modalidades estarían sometidas enteramente a la voluntad de las partes. Esta autonomía de los "contrayentes» con respecto a la sociedad no tan sólo sería predicable de las autoridades civiles o religiosas, sino 
que asimismo se extendería a todas aquellas esferas más próximas al individuo, como el vecindario, la comunidad local, el grupo de amigos o los propios familiares, que pudieran ejercer presión en uno u otro sentido. Esta actitud, que se halla presente de manera creciente entre la población, por más que sea de forma difusa y poco elaborada, no es más que uno de los muchos exponentes de una tendencia hacia la privatización de los comportamientos y de la moral familiares.

En el curso de la década de los años ochenta la familia se ha estado transformando. Bajo el manto de la nueva mayoría moral americana, que tal vez en el futuro podamos interpretar como el canto del cisne de la resistencia al cambio, un movimiento subterráneo de vastas proporciones está haciendo tambalear los cimicntos del sistema familiar vigente.

La crisis no es nueva. Desde los inicios de la industrialización se han alzado voces de moralistas y agoreros, tanto de derechas como de izquierdas, que pintaban con trazos negros el futuro de la familia y vaticinaban su final catastrófico inminente. Se trataba más que nada de designios o temores ideológicos de toda laya que no alcanzaban a hacer mella en el quehacer cotidiano de la mayor parte de las gentes, que seguían imperturbables sus vidas. Sin embargo, en el tiempo presente, ciertos comportamientos familiares atestiguan mutaciones radicales en los valores y en las instituciones. No es que la familia toque a su fin, es que sencillamente está cambiando a marchas forzadas.

Estamos asistiendo a lo que podríamos calificar de segunda transición de la familia. La primera se gestó a lo largo de muchos decenios al compás de la disminución drástica de sus funciones - funciones que quedaron reducidas a las relacionadas con la reproducción biológica y social-y de su contracción en torno al núcleo familiar estricto, en aquellos países o regiones en donde predominaba algún tipo de familia multigeneracional. Este proceso, que podemos designar con el nombre de nuclearización, ftte acompañado por fenómenos tales como é crecimiento del intervencionismo estatal y la aparición del Estado del bienestar junto con la creación de los planes de pensiones para los trabajadores, pero sobre todo por la difusión de la salarización a capas cada vez más amplias de la población. Con ello las unidades familiares dejaban de ser centros de producción, se limitaban únicamente al consumo y se producia, pues, una separación entre el ámbito del trabajo y el ámbito de la residencia, centrado este último en la familia.

La segunda transición familiar - cuyo objeto no es tanto las formas de la familia como la definición y los contenidos de ésta- presenta un carácter revolucionario por lo súbito y lo profundo de las transformaciones que estamos presenciando. En primer lugar, se cstá produciendo una difuminación de los límites entre legitimidad e ilegitimidad que, al menos en el caso de España, ha venido precedida por la desaparición de las diferencias jurídicas entre hijos na- 
turales y legítimos. La tendencia a la equiparación entre las situaciones de derecho y de hecho, que surten ahora ambas los mismos efectos, está favoreciendo la adopción de un critcrio más sociológico que jurídico en el enjuiciamiento y comprensión de los problemas que se plantean en el ámbito familiar.

No es que el matrimonio se esté desinstitucionalizando. Lo que sucede es que, en concurrencia con el mismo, diversas prácticas alternativas pugnan por obtener legitimación. La evolución de la que somos testigos es parecida a la experimentada por las instituciones religiosas, en cuyo curso la Íglesia Católica fue perdiendo su monopolio y tuvo que compartir su influencia con varias denominaciones y sectas. Desde el momento en que el matrimonio civil vino a competir con el eclesiástico se resquebrajó el carácter omnímodo de la institución y se instauró una actitud semejante a la indiferencia religiosa.

Así, pues, más que hablar de desinstitucionalización del matrimonio es más correcto pensar en un proceso de desmonopolización. Si bien la gran mayoría de las personas se siguen casando al menos una vez en su vida, algunas, sobre todo mujeres, optan voluntariamente por la soltería o posponen indefinidamente su unión matrimonial en aras de su promoción profesional. Por otra parte, para los que continúan casándose, el matrimonio tiende a convertirse en una fase vital más que en un proyecto vitalicio. Así, antes del matrimonio se está imponiendo cada vez más la cohabitación no marital como etapa de aprendizaje de los jóvenes, que no constituye más que un corolario de la aceptación general de las relaciones sexuales prematrimoniales. De esta forma, se está llegando a una especie de matrimonio a prueba, como proponía Margaret Mead. Por otra parte, la recomposición familiar tras un matrimonio fracasado se asienta generalmente sobre una unión consensual, al menos a partir de una cierta edad.

Pero lo realmente revolucionario no son tanto estos comportamientos, que al fin y al cabo en la actualidad son aún minoritarios entre el grueso de la población, sino su tolerancia o incluso aceptación por parte de casi todo el mundo. A nadie se le antoja hoy borrar a alguien del círculo de sus amistades porque esté separado, tenga un hijo fuera del vínculo matrimonial o cohabite con su pareja. Lo que ha cambiado básicamente es que ahora los protagonistas de esta historia ya no son marginados o lumpenproletarios, sino que se trata de personas perfectamente respetables, que tienen un buen empleo y se ganan bien la vida. Por otra parte, en ciertos ambientes incluso es de mal gusto preguntar o hacer averiguaciones sobre el estatuto matrimonial de uno. Se trata de algo privado, como la religión.

Lo que sale claramemente realzado de esta crisis es la pareja. Tanto a guisa de ideal como en la práctica de la vida cotidiara, la pareja se experimenta como más necesaria que nunca. Pero los visos remozados que está adoptando la nueva pareja son algo distintos a los de antaño. Es imposible entender la di- 
námica de la pareja actual sin tener en cuenta el incremento del individualismo y el atge del feminismo, dos fenómenos que constituyen signos característicos de nuestro tiempo.

Al hablar de feminismo - sin duda la gran revolución del ámbito íntimo en el siglo XX y uno de los mayores revulsivos que están subvirtiendo los valores dominantes - no me refiero tanto al movimiento feminista militante como a un cierto sentimiento difuso de igualitarismo sexual que impregna amplias capas y sectores de la población. Con la creación de centros universitarios de estudios feministas y de institutos de la mujer, el movimiento feminista ha perdido gran parte de su radicalismo y de sus militantes, al tiempo que sus instancias más institucionales se especializaban lógicamente en la lucha contra las desigualdades sexuales y contra las discriminaciones aún existentes entre hombres y mujeres. Pero, pese al declive del movimiento, muchos de los valores del feminismo han calado muy hondo entre la población femenina e incluso masculina. Así, muchas de las reivindicaciones planteadas por las feministas de los años sesenta que a la sazón podían parecer descabelladas y de imposible realización, actualmente son asumidas, puestas en práctica e incluso defendidas por mujeres que más bien profesan actitudes indiferentes y hasta hostiles al movimiento feminista.

El desarrollo del individualismo constituye otro de los rasgos distintivos de los cambios que se están produciendo en el interior de la pareja. El despliegue de la afectividad sigue constituyendo uno de los intereses vitales más importantes que mueven y unen a los individuos. Pero junto a la satisfacción afectiva, y en ocasiones frente a ella, aparece claramente la autorrealización personal en su conjunto como otro de los factores más relevantes que tiende a configurar las vidas de los individuos y, por ende, que conduce a la formación - o a la disolución- de las unidades de convivencia. La realización propia ha dejado de estar subordinada simplemente a los intereses económicos y a la crianza de los hijos y ha pasado a ser una de las claves que dan sentido a las vidas de los individuos y explican su curso. De esta forma, individualismo y feminismo, fenómenos presuntamente antitéticos, se llegan a dar la mano en la medida en que la ética de la autorrealización personal constituye precisamente el reverso de la actitud de sacrificio y resignación, virtudes tradicionalmente adscritas al mundo femenino.

Así, nos encontramos con la paradoja de que uno de los efectos imprevistos del feminismo es la intensificación del individualismo. A pesar de que un importante sector ideológico del movimiento feminista ha proclamado siempre los valores de solidaridad y de domesticidad como antídotos contra el supuesto mundo agresivo y competitivo de los varones, el resultado práctico de la incorporación de la mujer a todos los sectores laborales, incluidos los situados al más alto nivel, comporta la adopción progresiva por parte de las mu- 
jeres de ciertos valores asociados tradicionalmente al ámbito masculino. De esta forma, la pareja cuya unidad se basaba en la fusión de sus miembros a partir de su complementaridad disimétrica está dando paso a un nuevo complejo monogámico en el que tanto hombres como mujeres, pero sobre todo estas últimas, no renuncian fácilmente a sus derechos como personas, mantienen una cierta reserva frente al compañero y anteponen su autorrealización a otras consideraciones de índole social y económica. Se trata, pues, de una pareja en la que sus miembros exhiben unos perfiles mucho más individualistas que en el pasado, una pareja que compendia en su seno los valores de los años sesenta $y$ ochenta.

El crecimiento del individualismo y el apogeo del feminismo, dos de los signos más distintivos de la segunda transición familiar a la que hemos hecho alusión hace unos momentos, están relacionados con la intensificación de la privatización. Ésta constituye un vasto y dilatado proceso histórico, que arranca del Renacimiento y de la Reforma Protestante y que llega hasta nuestros días a través de diversas vicisitudes que han atravesado las sociedades industriales. Con la escisión de la vida social en las esferas pública y privada, surge un nuevo ámbito de relación social —el privado- donde existe una cierta autonomía respecto del control de la sociedad y donde los individuos aspiran a la pretensión de poder forjar sus propias normas de acuerdo con las creencias que profesan (Béjar, 1988; Flaquer, 1982). Esta escisión supone ante todo, como se ha dicho, la separación del ámbito de la producción con respecto al del consumo, del del trabajo con respecto al del ocio, y del de la factoxía y de la oficina con respecto al de la residencia. Implica también adoptar la fórmula de respeto a la intimidad que J.S. Mill enunciara en 1859, según la cual la única demarcación de la conducta de cualquier persona por la cual ésta es responsable ante la sociedad es la que afecta a los demás.

Representa, finalmente, el reconocimiento de la separación entre la Iglesia y el Estado. Al desaparecer la religión oficial, las manifestaciones de culto dejan de formar parte de la esfera pública y en el mejor de los casos pasan a revestir un aspecto puramente simbólico. De esta forma, la creencia religiosa se torna subjetiva y adquiere un carácter meramente privado. Así, se establece una especie de sintonía entre los fenómenos religiosos y los familiares, pues a medida que el Estado ya no necesita de la Iglesia para su legitimación, tiende también a relegar a segundo término a la familia como unidad básica de la sociedad civil, al poder establecer contacto directo con los individuos ciudadanos y prescindir de los cabezas de familia como intermediarios. Además, el avance de la secularización significa la multiplicación de las sectas y los mensajes religiosos, y a medida que ello sucede la moral sexual y familiar adopta formas diversas según clases sociales, niveles culturales y educativos y profesiones religiosas. El paralelismo entre religión y familia ilumina asimismo el 
proceso de confusión progresiva entre lo legítimo y lo ilegítimo. Cuando el matrimonio eclesiástico era de rigor, estaba muy claro lo que estaba bien y lo que estaba mal, pero cuando se empieza a aceptar la posibilidad de opción entre matrimonio religioso y civil, el monopolio de la verdad se diluye y tanto da celebrar los esponsales en la iglesia, en el juzgado o en la intimidad del lecho nupcial.

Decía más arriba que los cimientos del sistema familiar vigente se estaban tambaleando y que nos encontrábamos ante el umbral de un cambio de vastas proporciones cuyo alcance en el momento presente es todavía difícil de determinar. Hay quienes afirman que ello es debido a que la familia nuclear está en crisis. A mí me parece todo lo contrario. Todo cuanto está sucediendo nos indica precisamente que el ideal de la familia nuclear ha calado muy hondo entre la poblacion y que la lógica de su modelo se está desenvolviendo hasta las últimas consecuencias. La segunda transición familiar se puede interpretar justamente como la culminación del proceso de nuclearización. Según un principio establecido de la evolución social y cultural, la diferenciación estructural y la especificación cultural sólo son posibles en el momento en que una institución está firmemente implantada y arraigada. Buena parte de los cambios a que estamos asistiendo en el ámbito de la familia se relacionan con la diversificación del compañerismo familiar en el sentido que dan a esa expresión Burgess \& Locke (1945). En los años noventa, cuando la transición de la familia institucional a la basada en el compañerismo ya se ha completado del todo, esta dicotomía se nos antoja insuficiente y necesitamos nuevos conceptos que den cuenta de la evolución que se está registrando en el dominio privado.

La privatización familiar supone, más allá de una desparición gradual de vestigios institucionales del matrimonio, una progresiva individualización de los miembros de la pareja. Este proceso no afecta uniformemente a los diversos estratos y categorías, sino que como ha acaecido en otras épocas históricas, hay algunos sectores sociales que tiran del carro. En esta ocasión han sido las clases altas las primeras en apuntarse al matrimonio-asociación frente al matrimonio-comunidad, parafraseando a Ferdinand Tönnies. Así, a comienzos de los años noventa estamos viviendo la paradoja de que la clase media, que desde el siglo XVIII fue portaestandarte del amor romántico, en la actualidad está apostando fuertemente por el matrimonio individualista, mientras que la clase obrera se está convirtiendo en el baluarte de la intimidad fusional.

Ello es posible porque la privatización requiere precisamente la libertad de elección por parte del sujeto -en este caso, los sujetos son los miembros de la pareja- de las normas que van a regir sus relaciones personales. Pero, según Kellerhals et al. (1982), la no determinación obligatoria y explícita de un comportamiento por reglas sociales exteriores a los sujetos no significa que aquél 
no tenga nada que ver con la adscripción de éstos a los grupos más caracteristicos de nuestra sociedad. En tal caso, la regulación de la relación de pareja estaría más bien relacionada con la idiosincrasia personal o con las inclinaciones psicológicas de sus miembros. Ello significaría que, a causa de esta evolución, el ámbito privado dejaría de ser competencia de la sociología para pasar a caer dentro del dominio de la ciencia del comportamiento individual.

En realidad, sucede todo lo contrario. Según el autor citado, la privatización, lo que hace es intensificar la incidencia y la importancia de los factores de clase, puesto que al estar el ámbito familiar "vacío de normas", al llenarlo, los sujetos tienden a reflejar sus intereses y representaciones de clase. Así, cuando los miembros de la pareja tratan de definir su modelo conyugal se ven abocados a una negociación en la que se ven inducidos a hacer jugar el cálculo de probabilidades y de rentabilidades y a plantearse cuál es la estrategia y concepciones que les resultan más ventajosos. $Y$ entonces los recursos que les confiere su posición de clase se convierten en los elementos determinantes de la negociación. Es por ello por lo que los miembros de las clases altas, cuyos patrimonios materiales, cuyas representaciones simbólicas y curyos capitales educativos y culturales se diferencian netamente de los restantes colectivos sociales, tienden a elaborar estilos conyugales y de vida que tienden hacia el individualismo, puesto que éste les beneficia y resulta más congrtuente con su bagage social.

Por lo tanto, no debiera sorprendernos mucho que hoy sean las clases más acomodadas y que gozan de un nivel cultural más alto las que estén arrinconando la respetabilidad burguesa y rompan una lanza en favor de formas de matrimonio poco convencionales. A mayor individualismo, mayor probabilidad de que los que inician su convivencia marital sellen un pacto por el cual se dé origen a una especie de forma contemporánea del matrimonio de razón de antaño. En este contrato - realmente privado puesto que su vigencia queda sujeta a la voluntad unilateral de las partes - las situaciones de derecho y de hecho tienden a diluir su sentido y los vocablos legítimo o ilegítimo tienden a desaparecer de sus cláusulas.

\section{A GUISA DE CONCLUSIÓN}

Para concluir, quisiera hacer unas breves observaciones para tratar de atar algunos cabos que han quedado sueltos en el curso de mi exposición.

En primer lugar, hay que resaltar la diferencia radical existente entre las familias de hecho del pasado y del presente. Las primeras eran «familias sin hogar», hogares rotos aquejados por las lacras de lo que a veces se suele denominar eufemísticamente los "problemas sociales». Con el crecimiento 
espectacular de los «hogares sin familia» y con el impulso hacia la privatización evidenciado por la curiosa alianza que se da entre el individualismo y el feminismo, las nuevas familias de hecho presentan un aspecto totalmente remozado. Aunque desde el punto de vista de las formas son parecidas a las del pasado, sus contenidos difieren radicalmente.

Lo que marca la diferencia entre las familias de hecho del pasado y las del presente es el distinto grado de estigmatización social o discriminación jurídica de que son objeto sus miembros. Así, la estigmatización social que padecían los hijos de los separados o de madre soltera, la discriminación jurídica de los hijos naturales - mucho peor en el caso de los adulterinos-, afortunadamente han desaparecido ya. Nadie se escandaliza cuando se entera de que alguien convive maritalmente sin estar casado, de la misma forma que a éste último su estado no le acarrea problemas muy graves. En este contexto, una vez más el factor clase vuelve a configurarse como decisivo. Las dificultades con que podía tropezar en la vida el hijo natural de una familia pobre y marginada (donde nacía la gran mayoría de los hijos ilegítimos en el pasado), y las oportunidades de que gozará probablemente el hijo - también natural- de una pareja de profesores universitarios de los años noventa, cuyos miembros han decidido cohabitar de forma permanente, constituyen escenarios vitales absolutamente distintos.

En segundo lugar, los demógrafos, sociólogos y demás especialistas de la familia de nuestro tiempo tienen que hilar mucho más fino que sus predecesores, pues si quieren que sus categorías sean sociológicamente significativas, es preciso que elaboren nuevas tipologías y hagan distingos que no eran necesarios en tiempos anteriores. Algo de eso hemos visto en lo que respecta a las uniones consensuales, pero ello se podría aplicar a muchos otros casos. Además, no basta con introducir tipos de hogar inexistentes en el pasado, sino que es necesario confrontar continuamente las formas que presentan con sus contenidos internos.

La multiplicidad de situaciones inéditas no tan sólo obedece a la proliferación de nuevas formas de hogar que están disputando terreno a los hogares uninucleares, sino al surgimiento, dentro del caparazón de cada una de estas formas de hogar, de una gran riqueza de matizaciones según las clases sociales, los credos religiosos y los niveles culturales. No tan sólo es preciso distinguir entre las categorías de legítimo e ilegítimo, que pronto van a quedar desfasadas, sino que hay que prestar atención a factores o circunstancias extrínsecos a la familia que tienden a configurar los tipos de hogar sociológicamente relevantes. Ello supondrá un esfuerzo de imaginación de los especialistas sobre la familia, quienes transformados en lingüistas de fortuna tendrán que esforzarse para dar nombre a los nuevos fenómenos que van apareciendo en el magma proteico del ámbito familiar. 
¿Hogares sin familia o familias sin hogar?

\section{BIBLIOGRAFIAA}

Alabart, Anna; Cabré, Anna; Domingo, Andreu; Fabré, Assumpta \& Stolcke, Verena (1988). La cobabitación en España: Un estudio en Madrid y Barcelona, Madrid: Centro de Investigaciones Sociológicas.

Alberdi, Inés (1978). Historia y sociología del divorcio en España, Madrid: Centro de Investigaciones Sociológicas.

Alberdi, Inés (1986). «Divorcio y sociedad en la España actual», Sistema, 70, pp. 93-112.

Alonso Hinojal, Isidoro (1973). Sociología de la familia. Madrid/Barcelona: Guadiana.

Anales de moral social y económica (1967). La familia española, Madrid: Centro de Estudios Sociales de la Santa Cruz del Valle de los Caídos.

Anderson, Michael (ed.) (1971). Sociology of the family, Harmondsworth: Penguin.

Ariès, Philippe (1960). L'enfance et la vie familiale sous l'Ancien Régime, París: Plon.

Barbagli, Marzio (1984). Sotto lo stesso tetto: Mutamenti della famiglia in Italia dal XV al XX secolo, Bologna: Il Mulino.

Bawin-Legros, Bernardette (1988). Familles, mariage, divorce: Une sociologie des comportements familiaux contemporains, Liège/Bruxelles: Pierre Mardaga éditeur.

Béjar, Helena (1988). El ámbito intimo: Privacidad, individualismo y modernidad, Madrid: Alianza Editorial.

Bell, Colin (1968). Middle Class Families: Social and Geographical Mobility, London: Routledge \& Kegan Paul.

Beltrán, Miguel et al. (1987). Estudio sobre la familia española, Madrid: Ministerio de Trabajo y Seguridad Social.

Bonvalet, Catherine \& Merlin, Pierre (1988). Les transformations de la famille et de l'babitat, París: Ministère des Affaires Sociales et de l'Emploi/La Documentation Française.

Breton, Françoise \& Barruti, Lorea (1978). La família i el parentiu, Barcelona: Dopesa.

Burgess, Ernest W. \& Locke, Harvey J. (1945). The Family: From Institution to Companionship, New York: American Book Co.

Buunk, Bram P. \& Driel, Barry van. (1989). Variant Lifestyles and Relationships, London: Sage.

Campo, Salustiano del (1960). La familia española en transición, Madrid: Ed. del Congreso de la Familia.

Campo, Salustiano del (1982). La evaluación de la familia española en el siglo XX, Madrid: Alianza Editorial.

Campo, Salustiano del (1984). «Familia» en Salustiano del Campo (ed.) Tratado 
«Papers»: Revista de Sociologia

de sociología, Madrid: Taurus, Vol. 2, pp. 9-33.

Campo, Saltustiano del \& Navarro López, Manuel. (1985). Análisis sociológico de la familia española, Barcelona: Ariel.

Campo, Salustiano del \& Navarro López, Manuel (1987). Nuevo análists de la población española, Barcelona: Ariel.

Conde, Rosa. (ed.) (1982). Familia y cambio social en España, Madrid: Centro de Investigaciones Sociológicas.

Conde, Rosa (1982). "Desarrollo económico y cambio familiar: El impacto del nuevo rol femenino sobre la estructura de la familia» en Rosa Conde (ed.) (1982), pp. 135-165.

Díez Nicolás, Juan (1983). "La familia en Europa y el cambio social", Revista española de investigaciones sociológicas, 21: 11-31.

Domingo i Valls, Andreu (1989). "La cohabitación: En los orígenes de una nueva moral", El Ciervo, n'455 (enero): 9-11.

Donati, Pierpaolo (1986). La famiglia nella società relazionale: Nuove reti e nuove regole, Milano: Angeli.

Donati, Pierpaolo (1989). La famiglia come relazione sociale, Milano: Angeli.

Donzelot Jacques (1979). La policia de las familias, Valencia: Pre-textos.

Engels, Federico (1970). Elorigen de la familia, de la propiedad privada y del $E_{5-}$ tado, Madrid: Fundamentos.

Familia y estado (1982). Número monogxáfico de Papers. Revista de sociología, $N^{\circ} 18$, Barcelona: Península.

Ferrándiz, Alejandra \& Verdú, Vicente (1974). Noviazgo y matrimonio en la burguesía española, Madrid: Cuadernos para el Diálogo.

Flandrin, Jean-Louis (1979). Orígenes de la familia moderna, Barcelona: Crítica.

Flaquer, Lluís (1982). De la vida privada, Barcelona: Edicions 62.

Flaquer, Lluís (1986a). «Privatización o desprivatización: Contribuciones recientes a la sociología de la familia", Papers. Revista de sociología, 27: 157-172.

Flaquer, Lluís (1986b). "Family, Residence and Industrialisation in Northern Catalonia: Legal and Social Aspects», Sociologia Ruralis 16: 268-284.

Flaquer, Lluís (1990). "La familia española: Cambio y perspectivas" en Salvador Giner (ed.) España: Sociedad y política. Madrid: Espasa Calpe, pp. 509-549.

Flaquer, Lluís \& Soler, Joan, "La soledad en la sociedad urbana», Barcelona: $M e-$ trópolis Mediterrania, $\mathrm{n}^{\circ} \mathrm{6}$, octubre-diciembre, pp. 141-146.

Flaquer, Lluís \& Soler, Joan (1990). Permanencia y cambio en la familia española, Madrid: Centro de Investigaciones Sociológicas.

Fortes, Meyer (1958). "Introduction» en Jack Goody (ed.) (1958), pp. 1-14.

Fox, Robin (1972). Sistemas de parentesco y matrimonio, Madrid: Alianza Editorial.

Freeman, Michael D.A. \& Lyon, Christina M. (1983). Cohabitation without Marriage: An Essay in Law and Social Policy, London: Gower.

Fromm, Erich, Horkheimer, Max Parsons, Talcott et al. (1970). La familia, Barcelona: Península.

Fundación Foessa (1970). Informe sociológico sobre la situación social de España, Madrid: Euramérica.

Fundación Foessa (1976). Estudios sociológicos sobre la situación social de España, Madrid: Euramérica. 
Fundación Foessa (1983). Informe sociológico sobre el cambio social en España 1975/1983, Vol. II, Madrid: Euramérica.

García Ferrando, Manuel (1987). «I La investigación sociológica sobre la familia en España, 1959-1984» en Miguel Beltrán et al. (1987), pp. 297-352.

Giddens, Anthony (1982). Sociology: A Brief but Critical Introduction, London: Macmillan.

Glick, Paul C. (1947). «Updating the Life Cycle of the Family", Journal of Marriage and the Family 39: 5-13

Glick, Paul C. (1977). "The Family Cycle», American Sociological Review 12: 164-174.

Gómez Arboleya, Enrique \& Campo, Salustiano del (1959). Para una sociología de la familia española, Madrid: Ed. del Congreso de la Familia.

Goode, William J. (1966). La familia, México: U.T.E.H.A.

Goody, Jack. (ed.) (1958). The Developmental Cycle in Domestic Groups, Cambridge: Cambridge University Press.

Harris, C.C. (1986). Familia y sociedad industrial, Barcelona: Península.

Iglesias de Ussel, Julio (1979). El aborto: Un estudio sociológico sobre el caso español, Madrid: Centro de Investigaciones Sociológicas.

Iglesias de Ussel, Julio (1983). «La sociología de la sexualidad en España: Notas introductorias», Revista española de investigaciones sociológicas 21: 103-133.

Iglesias de Ussel, Julio (1986). «La situación de la familia en España y los nuevos modelos familiares" en Situación social de la mujer en España, Madrid: Instituto de la Mujer (Ministerio de Cultura), pp. 65-128.

Iglesias de Ussel, Julio (1987). Sociologia del noviazgo en España, Granada: Caja General de Ahorros y Monte de Piedad de Granada.

iglesias de Ussel, Julio (1988). «Conflictos matrimoniales y desorganización familiar en España» en Juan del Pino Artacho (ed.), El conflicto social, Málaga: Centro Asociado de la U.N.E.D. en Málaga, Departamento de Sociología de la Universidad de Málaga.

Iglesias de Ussel, Julio (ed.) (1988). Las familias monoparentales, Madrid: Instituto de la Mujer (Ministerio de Asuntos Sociales).

Instituto de Sociología Aplicada de Madrid (1976). Estudio sociológico de la familia española, Madrid: Confederación Española de Cajas de Ahorros:

Izquierdo, María Jesús, Miguélez, Fausto \& Subirats, Marina (1978). Enquesta Metropolitana 1986: Condicions de vida i hàbits de la població de l'àrea metropolitana de Barcelona, Vol. I (Informe general), Barcelona: Institut d'Estudis Metropolitans.

Izquierdo, María Jesús (1989). "Las viejas: Una soledad callada» en El Ciervo, número monográfico sobre "La familia y nuevas formas de convivencia», $n^{\circ} 455$, enero, pp. 11-13.

Kellexhals, \}. et al. (1982). Mariages au quotidien: Irégalités sociales, tensions culturelles et organisation familiale, Lausanne: Éditions Pierre-Marcel Favre.

Kellerhals, J. et al. (1984). Microsociologie de la famille, París: Presses Universitaires de France.

Lamo de Espinosa, Emilio (1983). "¿Tiene futuro la familia?», El País, 13 de febrero, pp. 10-11. 
"Papers": Revista de Sociologia

Lamourère, Odile (1988). Los que vivimos solos. La soledad ya no es lo que era, Barcelona: Paidos.

Lasch, Christopher (1984). Refugio en un mundo despiadado. La familia: ¿Santuario o institución asediada?, Barcelona: Gedisa.

Laslett, Peter \&. Wall, Richard (eds.) (1972). Housebold and Family in Past Time, Cambridge: Cambridge University Press.

Le Gall, Didier \& Martin, Claude (1987). Les familles monoparentales: Évolution et traitement social, París: Les Éditions ESF.

MacFarlane, Alan (1936). Marriage and Love in England 1300-1840, Oxford: Basil Blanckwell.

Marsden, Dennis (1969). Mothers Alone: Poverty and the Fatberless Family, London: Allen Lane the Penguin Press.

Michel, Andrée (1974). Sociología de la familia y del matrimonio, Barcelona: Península.

Mill, John Stuart (1983). Sobre la libertat, Barcelona: Laia.

Mitterauer, Michael \& Sieder, Reinhard (1982). The European Family, Chicago: The University of Chicago Press

Morgan, D.H.J. (1975). Social Theory and the Family, London: Routlege and Kegan Paul.

Parsons, Talcott \& Bales, Robert F. (1955). Family, Socialization and Interaction Process, New York: The Free Press.

Reher, David-Sven (1984). «La importancia del análisis dinámico ante el análisis estático del hogar y la familia: Algunos ejemplos de la ciudad de Cuenca en el siglo XIX", Revista española de investigaciones sociológicas 27: 107-135.

Reher, David-Sven (1988). Familia, población y sociedad en la provincia de Cuenca, 1700-1970, Madrid: Centro de Investigaciones Sociológicas.

Roussel, Louis (1980). "Mariages et divorces. Contribution à une analyse systématique des modèles matrimoniaux", Population 35: 1025-1040.

Roussel, Louis (1983). "Les ménages d'une personne: L'évolution récente", Population 6: 995-1016.

Roussel, Louis (1986). «Évolution récente de la structure des ménages dans quelques pays industriels", Population 41 (6): 913-934.

Roussel, Louis (1989). La famille incertaine, París: Éditions Odile Jacob.

Segalen, Martine (1981). Sociologie de la famille, París: Armand Colin.

Soler Serratosa, Joan (1985a). «La estructura del hogar en Barcelona: Un análisis del padrón de 1981", Boletín de la Asociación de Demografia Histórica 3: 51-75.

Soler Serratosa, Joan (1985b). «EI envejecimeinto de la población: Un reto para los servicios sociales», Fer ciutat, 12 (julio-septiembre): 4-9.

Trost, Jan (1978). «Married and Unmarried Cohabitation in Sweden", en Marie Corbin (ed.) The Couple, Harmondsworth: Penguin, pp. 158-168.

Valero, Ángeles \& Pascual, Rosa María (1988). Estructura del bogar y de la familia en España, 1981, Madrid: Centro de Investigaciones Sociológicas (trabajo inédito).

Villar, Pierre et al. (1987). La familia en la España mediterránea, Barcelona: Crítica. Young, Michael \& Wilmott, Peter (1957). Family and Kinship in East London, London: Roułledge \& Kegan Paul. 